Viroj Wiwanitkit

\title{
Renal failure due to djenkolism: an appraisal of previously reported Thai cases
}

\section{To the Editor}

Many tropical plants may induce intoxication that ranges from annoying to life-threatening. ${ }^{1}$ Djenkol bean, a local food in Southeast Asian countries, especially in southern Thailand and Malaysia, is considered to be a plant that can cause intoxication, called "djenkolism". Generally, features of acute djenkolism include nausea, vomiting, bilateral loin pain, gross hematuria, and oliguria. ${ }^{2}$ Some patients develop more serious manifestations including acute renal failure. ${ }^{1,2}$ Nephropathy due to djenkolism is a rare disorder, which can lead to death as a consequence. ${ }^{1,2}$ Based on its chemistry, djenkol bean-associated acute renal failure may be analogous to acute uric-acid nephropathy. ${ }^{2}$ In southeast Asian tropical countries, eating djenkol bean is traditional; however, only a few people show intoxication and fewer still present with severe manifestation. The author has summarized previously reported Thai cases of djenkolism and assessed the magnitude of acute renal failure (ARF) due to djenkolism.

Here, the author reports this ministudy, carried out in order to appraise the renal manifestations and treatment in the reported Thai patients with djenkolism. A literature review of articles concerning ARF due to djenkolism in Thailand was performed from the database of the published works cited in the Index Medicus and Science Citation Index. The author also reviewed the published works in all 256 local Thai journals, which are not included in the international citation index. Reports that contained in complete data were excluded from the analysis.
According to this review, there were three reports ${ }^{3-5}$ covering seven patients with djenkolism. Their ages ranged between 12 and 50 years. Two of the seven patients were aged under 15 years. There were five males and two females. The number of ingested djenkol beans varied from 15 to 50. All seven patients had nausea, vomiting, bilateral loin pain, and gross hematuria. Oliguria was noted in two patients and ARF was diagnosed in one patient (14.3\%). The management of djenkolism includes rest and supportive and symptomatic treatment; the principle is to change the urine $\mathrm{pH}$ from acidic to alkaline by administrating intravenous NaHCO3. ${ }^{3-5}$ With these therapies, all seven patients, including the one with ARF, had a complete recovery. The author hereby concludes that djenkolism is a rare intoxication that can lead to gross hematuria in subjects in endemic areas. Hospitalization is necessary for close monitoring for ARF in patients with djenkolism.

\section{References}

1. Jha V, Chugh KS. Nephropathy associated with animal, plant, and chemical toxins in the tropics. Semin Nephrol 2003;23:49-65.

2. Segasothy M, Swaminathan M, Kong NC, Bennett WM. Djenkol bean poisoning (djenkolism): an unusual cause of acute renal failure. Am J Kidney Dis 1995;25:63-6.

3. Areekul S. Djenkol bean, djenkolic acid and djenkolism. J Med Assoc Thai 1979;62:527-31.

4. Prawitpaiboon M. Djenkolism from eating of djenkol beans. Thai $\mathbf{J}$ Health Environ 1988;10:119-23.

5. Kasetjaroen Y, Wattanayakorn W, Sereekul S, Denpreecha V, Aranchaiya A. Djenkolism: report of cases. Bull Dept Med Serv 1985;10:651-6. 